\title{
An Overview of Treatment of Crush Syndrome
}

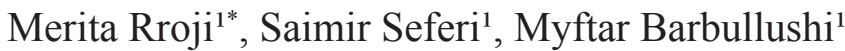

Received: 03 January 2021 / Accepted: 15 January 2021 / Published online: 20 January 2021

(C) The Author(s) 2021. This article is published with open access at https://journal.astes.org.al

\begin{abstract}
Natural mass disasters directly or indirectly affect huge populations, who need basic infrastructural help and assistance to survive. However, despite the potentially negative impact on survival chances, the authorities often dismiss these health care issues.

This impact is of great importance, especially in the emerging world, where the casualty rates are much higher because of inappropriate building materials and lack of appropriate construction standards. Thus, massive destruction can occur with earthquakes of even moderately low magnitude.

The first description of the crush syndrome appeared in the modern medical literature after the Messina earthquake in 1909. Since crush syndrome is quite rare in daily practice, mistakes are frequent in treating these cases.

This review summarizes the etiopathogenesis of traumatic rhabdomyolysis and crush syndrome based acute kidney injury. The clinical and laboratory features, prophylaxis, and treatment of crush cases are described as well.

The importance of early and dynamic fluid resuscitation is indicated for the prophylaxis of acute kidney injury. Treatment of both acute and chronic kidney diseases (CKDs) is especially problematic after disasters because they almost always require complex technology and equipment, whereas specific drugs may be difficult to obtain to treat chronic kidney patients.

Although crush syndrome is a major cause of mortality in the rescued victims of massive earthquakes, the number of deaths due to crush syndrome (or fatalities of renal disaster) can be decreased by appropriate management.

Keywords: crush syndrome, acute kidney injury, traumatic rhabdomyolysis
\end{abstract}

\section{Introduction}

Disasters are unexpected catastrophes causing massive material damage and suffering; residents of the involved area may become homeless, be wounded, or die. Although some disasters are human-made, in general, most of them are natural geological or meteorological events.

There are many natural catastrophes like Kashmir, Iran, Haiti, Marmara, Japan earthquakes, which have affected densely populated and/or geographically extensive areas directly or indirectly, where necessary infrastructural help

Original article, no submission or publication in advance or in parallel

\footnotetext{
* Corresponding author:

Merita RROJI, MD, Ph.D.,

\meritarroji@yahoo.com

1 Department of Nephrology, University Hospital Center" Mother Teresa", Tirana, ALBANIA.
}

is needed and support to survive. According to the detailed statistics, during the Marmara-Turkey 1999 earthquake, nearly 16000000 people were somehow affected by the disaster $[1,2]$.

This figure includes displaced populations, those who lost their jobs due to economic collapse and deprivation, and those who lost properties [3] where $>130000$ buildings collapsed entirely, making 600000 people homeless. There were reported 51 deaths and up to 750 people injured, and 12,181 people were reported to be living in temporary accommodation during the earthquake of 26 November 2019 in Albania. This impact is of great importance, especially in the emerging world, where the casualty rates are much higher because of inappropriate building materials and lack of appropriate construction standards. Thus, massive destruction can occur with earthquakes of even moderately low magnitude.

Clinical crush syndrome is presented frequently in traumatic injury in disasters, where rhabdomyolysis is one of the leading causes of acute renal failure (ARF). The first description of the crush syndrome appeared in the modern medical literature after the Messina earthquake in 1909 [2]. 
Trauma-related crush syndrome was first identified as a single/broad pathophysiologic entity in 1941. During the bombing of London, Bywaters and Beall described the clinical picture in four crush cases. Three of them were oliguric, and all produced dark brownish urine. All four patients died; histopathological examination of the kidneys revealed pigmented casts, polymorphonuclear invasion, and acute tubular necrosis (ATN). The true incidence of acute kidney injury in rhabdomyolysis is not easy to establish depending on various definitions and clinical scenarios. The incidence of acute kidney injury due to rhabdomyolysis was higher among persons who had undergone trauma [4]. The term 'acute kidney injury' (AKI) was substituted as a pathophysiological better option to the earlier definition of acute renal failure, and this term was suggested to be used for disaster crush casualties. AKI with impact on clinical outcome is accepted to be present in case of an abrupt (within $48 \mathrm{~h}$ ) reduction in kidney function defined either as an absolute 1.5-fold increase in serum creatinine or by 0.5 $\mathrm{mg} / \mathrm{dl}$ or a decrease in glomerular filtration rate by $50 \%$, and/or a reduction in urine output to below $0.5 \mathrm{ml} / \mathrm{kg} / \mathrm{h}$ for $46 \mathrm{~h}$ [5]. This notion means that even small changes in kidney function may profoundly alter the outcome.

\section{Physiopathology of AKI:}

The histopathologic lesion in crash-related AKI is ATN, in which hypovolemic (ischemic) and nephrotoxic factors play a role. Crushed patients frequently develop hypovolemic shock in the first few hours after extrication from under the rubble. Hypovolemia etiologies are numerous, including lack of oral fluid intake, hemorrhage from associated injuries, and profound third spacing. By releasing the external pressure, intravascular fluids flow into the intracellular compartments, and the injured area begins to sequester large volumes of fluids (compartment syndrome).

Limbs can hold up to $12 \mathrm{~L}$ of fluid in their large compartments. Besides, the distributive shock also can develop from the release of inflammatory mediators caused by reperfusion injury. Hypovolemia then can lead to further ischemia and cell death. Acidemia often accompanies these metabolic derangements, in large part owing to ongoing hypoperfusion. AKI often is prerenal at first, with later evolution into ATN if hypovolemia is not appropriately treated $[6,7]$.

Muscle trauma, although the primary injury that happens, does not always lead to rhabdomyolysis, not all rhabdomyolysis leads to ARF, and not all ARF related to the crush syndrome is attributable to rhabdomyolysis [6].

Rhabdomyolysis refers to the disintegration of striated muscle release of muscular cell constituents into the extracellular fluid and the circulation [8]. Trauma and muscle compression are believed to cause rhabdomyolysis through direct injury to the muscle, resulting in disruption of the sarcolemma and direct leakage of cell contents driving to an unregulated increase in intracellular calcium. Sarcoplasmic calcium is strictly regulated by a series of pumps, channels, and exchangers that maintain low calcium levels when the muscle is at rest and enables the increase needed for actinmyosin binding and muscle contraction.

Depletion of ATP impairs the role of these pumps, resulting in a persistent increase in sarcoplasmic calcium that leads to persistent contraction and energy depletion and the activation of calcium-dependent neutral proteases and phospholipases; the result is the eventual destruction of myofibrillar, cytoskeletal, and membrane proteins, followed by lysosomal digestion of fiber contents. Ultimately, the myofibrillar network breaks down, disintegrating the myocyte [4-6]. Myoglobin is one of the critical compounds being extensively released in circulation after trauma, and myoglobinuria is the central element in the development of rhabdomyolysis-induced ARF. Myoglobin, an 18,800-Dalton oxygen carrier, is like hemoglobin but contains only one heme moiety.

Usually, only small amounts of myoglobin reach the urine because it is mainly bound to plasma globulins. When massive amounts of myoglobin are released, the binding capacity of the plasma protein is exceeded. Myoglobin is then filtered by the glomeruli and reaches the tubules, where it may cause obstruction and renal dysfunction [2, 8]. The obstruction happens when myoglobin precipitate in combination with the Tamm-Horsfall protein, forming tubular casts, especially in the presence of acid $\mathrm{pH}$. This process is promoted by volume depletion, resulting in concentrated urine. Acute kidney injury associated with myoglobinuria is a common complication of both traumatic and non-traumatic rhabdomyolysis [8], and it may be lifethreatening. It may manifest from a subclinical rise of creatine kinase $(\mathrm{CK})$ to a medical emergency comprising interstitial and muscle cell edema, intravascular volume contraction, and pigment-induced acute renal failure (ARF).

In patients with rhabdomyolysis generated by trauma, further injury occurs from ischemia-reperfusion and inflammation by neutrophils that infiltrate injured muscle. Reperfusion injury during crush syndrome causes muscle ischemia due to tissue pressure that exceeds capillary perfusion pressure. The reperfusion, which happens when the compression is relieved (ischemia-reperfusion injury), represents rhabdomyolysis's fundamental pathophysiologic mechanism. When compression is removed, amongst others, leukocytes migrate into the injured tissue, where they are activated and release free radicals and other injurious compounds. Superoxide, the anion form of oxygen $\left(\mathrm{O}_{2}^{-}\right)$, and hydrogen peroxide $\left(\mathrm{H}_{2} \mathrm{O}_{2}\right)$ react to form the hydroxyl radical, which, in a large enough concentration, damages cellular molecules and causes lipid peroxidation [9, 10]. Lipid peroxidation leads to cell membrane destruction and cell lysis [11]. This damage leads to a further increase in fluid, calcium, and sodium absorption into the damaged cells.

Alternative causes of ARF in patients with crush injury are sepsis and drug nephrotoxicity [8]. 


\section{Diagnostic:}

Myoglobin's measurement in plasma or urine is unreliable for diagnostic purposes because myoglobin is metabolized in the liver quickly and in an unpredictable fashion. On the other hand, the enzyme creatine kinase (CK) is ubiquitously present in striated muscle (CKMM) and is the more stable marker to assess muscle damage's presence and intensity than is myoglobin.

Phosphorus and potassium are elevated while calcium is reduced. Massive lysis of muscle cells substantially increases potassium in circulation. Renal insufficiency and acidosis increase the potassium levels further on. Hyperkalemia is a life-threatening condition; its pathogenesis is multifactorial (with causes such as massive tissue destruction, acidosis, lysis of transfused red blood cells, or decreased urinary potassium excretion caused by renal failure) and needs immediate treatment due to potassium cardiotoxicity. Hyperkalemia is the most critical laboratory abnormality. In the presence of hyperkalemia, hypocalcemia may lead to severe cardiac arrhythmias. Portable electrocardiography machines may be useful to detect life-threatening hyperkalemia in disaster fields. Further on the course of the disease hypercalcemia is present.

Phosphorus is released by damaged muscle resulting in hyperphosphatemia. Renal insufficiency is also a cause of hyperphosphatemia, which causes deposition of calcium-phosphate complexes in tissues and suppresses 1a-hydroxylase, the enzyme responsible for producing the active vitamin $\mathrm{D}$, contributing further to hypocalcemia. The diuresis should be carefully monitored, and renal biomarkers showed to be followed [2, 4-6].

\section{Management of Crush syndrome acute renal failure}

The main principle in the management of Crush syndrome to prevent AKI is administering fluids to prevent hypovolemia and hypoperfusion. Inadequate Alternatively delayed fluid administration increases the risk of AKI. Although considered crucial, the treatment and the amounts of fluids should be individualized, taking into account the time into the rubble, length of extrication procedure, volume status, and diuresis, characteristics of the patients (age, BMI, etc.), and environmental conditions.

Isotonic saline is the first and the best option for volume replacement because it helps to prevent AKI and carries a low risk for complications. Besides, sodium bicarbonate solutions added to half-isotonic saline could prevent tubular deposition of myoglobin and uric acid, correct metabolic acidosis reduces hyperkalemia but is not always available in chaotic circumstances [5]. Not all fluids are safe in crush syndrome; solutions containing even small amounts of potassium (e.g., Ringer lactate) should be avoided because fatal hyperkalemia may occur at any moment, even in the absence of renal failure [12].
There is some controversy about mannitol's administration to disaster crash victims, and it should not be administered to all crush patients. Mannitol has diuretic, antioxidant, and vasodilatory properties; prevents renal tubular cast deposition; expands extracellular volume; and reduces intercompartmental pressure, muscle edema, and pain. It is important to be underlined that mannitol may replace or extend the time for a surgical fasciotomy [13]. On the other hand, mannitol requires very close monitoring, which is very difficult in disasters because it may cause congestive heart failure and nephrotoxicity [14], and it requires close monitoring, which is often impossible after massive disasters. The decision to administer mannitol should be individualized, response to a test dose should first be assessed, with continuation only in a positive urinary response.

Loop diuretics are not recommended to be used routinely in the treatment of AKI. However, these agents may be useful in managing volume overload and theoretically could limit renal injury by enhancing tubular fluid flow, flushing out obstructive debris, converting oliguric AKI into nonoliguric AKI, reducing active tubular sodium reabsorption [15]. Decreasing renal oxygen consumption is evidence that they are not beneficial in this case and increase the risk of mortality. They could acidify the urine and increase the risk of cast formation and worsen hypocalcemia by inducing calciuria [16].

In crushed patients, shifting of calcium into the muscles, together with another risk factors like hyperphosphatemia, suppressed calcitriol synthesis, resistance to parathyroid hormone, and kidney failure, may expose them to hypocalcemia [17], which increase the risk for clinical symptoms that associate it like tetany, seizures, and cardiotoxicity $[2,18]$. A question may arise if hypocalcemia should be treated? After the first period of hypocalcemia, crush cases are essential to note that hypocalcemia, present during the crush syndrome, should not be treated unless patients are symptomatic hypocalcemia is symptomatic.

Hypercalcemia is frequent in crush victims, especially during recovery, because of the mobilization of the previously precipitated calcium salts from the muscles, the return of sensitivity to parathyroid hormone, and recovery of vitamin D synthesis [19]. During hypercalcemia, which is more common in crush patients who previously received calcium salts, tissular calcium precipitation may trigger cell damage and subsequent complications [4, 20, 21]. Hence, to avoid this, hypocalcemia should be treated only in case of symptoms.

Fasciotomy can effectively decrease the pressure and prevent distal ischemia, irreversible neurologic damage and soft tissue, renal failure, and bone infection [22]. However, fasciotomy takes the risk of infections [23] linked with open wounds, enhancing sepsis, amputation, chronic nerve dysfunction, hemodynamic instability, and death [5].

Fasciotomy is indicated when distal pulses are absent; it needs debridement of necrotic muscle and when the 
intercompartmental pressures are higher than 30-40 $\mathrm{mmHg}$ [24].

Clinical symptoms like refractory hypercalcemia, hyperkalemia, metabolic acidosis, or refractory oligoanuria need the use of renal replacement therapy. The two alternatives to RRT, conventional hemodialysis, or continuous renal replacement therapy (CRRT), could be used. Conventional hemodialysis does not eliminate myoglobin because of its high molecular weight. However, some authors refer that high-flux dialyzers can make a difference in myoglobinuric AKI. However, hemodialysis resolves the effects of renal dysfunction such as uremia and fluid overload, and electrolyte abnormalities. Plasma exchanges with plasmapheresis have also produced good results in cases of rhabdomyolysis $[2,4,21,26]$. When it is not possible for hemodialysis modality, peritoneal dialysis can be used, although we can have a slower potassium clearance [26].

The increased mortality in AKI is linked with infectious, pulmonary, cardiovascular, hematologic, gastrointestinal, neurologic, and psychiatric complications. It is unclear which victims will develop a full-blown crush syndrome, although the risk increases with trauma severity. Monitoring all clinical signs, such as brownish urine, oliguria, weight gain, edema, carefully makes able to early hospitalized high-risk patients $[2,21,27]$ and reducing this risk.

\section{Conclusion}

Medical and logistic principles in disaster victims may differ from those of routine practice, so we need to be aware of this. The published "Recommendations for the Management of Crush Victims in Mass Disasters" by ERBP may effectively guide the health care system to manage disaster victims with renal problems correctly and improve patients' outcomes.

COI Statement: This paper has not been submitted in parallel. It has not been published nor submitted for consideration beforehand.

This research received no specific grant from any funding agency in the public, commercial, or nonprofit sectors. There are no relevant or minor financial relationships from authors, their relatives or next of kin with external companies.

Disclosure: The authors declared no conflict of interest. No funding was received for this study.

Acknowledgement: We would like to thank medical staff of Department of Nephrology, University Hospital Center" Mother Teresa", Tirana, ALBANIA.

\section{References:}

1. Hashemi B, Safari S, Hosseini M, et al. A Systematic Review of Iranian Experiences in Seismo-Nephrology. Arch Trauma Res. 2016;5(2):e28796.

2. Sever MS,Lameire N, Biesen WV, Vanholder R. Disaster nephrology: a new concept for an old problem. Clin Kidney J. 2015; 8: 300-309.

3. Reports of Statistics Institution of the Turkish Prime Ministry. Crisis Center of the Turkish Prime Ministry, Ankara, 1997, pp: 3-15. Crush syndrome and acute kidney injury in disaster.

4. Sever MS, Vanholder R, Lameire N. Acute Kidney Injury in Active Wars and Other Man-Made Disasters. Semin Nephrol. 2020; 40(4):341-353.

5. Sever MS, Vanholder R. Management of crush victims in mass disasters: highlights from recently published recommendations. Clin J Am Soc Nephrol 2013; 8:328.

6. Vanholder R, Sever MS, Erek E, Lameire N. Acute renal failure related to the crush syndrome: towards an era of seismo-nephrology? Nephrol Dialysis Transplant 2000; 15(10): 1517-1521.

7. Zager RA. Rhabdomyolysis and myohemoglobinuric acute renal failure. Kidney Int1996; 49: 314-326.

8. Gabow PA, Kaehny WD, Kelleher SP. The spectrum of rhabdomyolysis. Medicine1982; 61: 141-152.

9. Cervellin G, Comelli I, Benatti M, Sanchis-Gomar F, Bassi A, Lippi G. Non-traumatic rhabdomyolysis: Background, laboratory features, and acute clinical management. Clin Biochem. 2017;50(12):656-662.

10. Panizoa N. Navarrob AR, Amaro-Villalobosb JM, et al. Molecular Mechanisms and Novel Therapeutic Approaches to Rhabdomyolysis-Induced Acute Kidney Injury. Kidney Blood Press Res 2015;40:520-532.

11. Civetta J,TaylorR, \& Kirby, R. Critical care 1997 (3rd ed.). Philadelphia: Lippincott-Raven.

12. Sever MS, Erek E, Vanholder R, Kantarci G, Yavuz M, Turkmen A, Ergin H, Tulbek MY, Duranty M, Manga G, Sevinir S, Lameire N; Marmara Earthquake Study Group: Serum potassium in the crush syndrome victims of the Marmara disaster. Clin Nephrol 2003;59: 326-333, 2003.

13. OS, Rubinstein I, Weaver JM, Knochel JP: Mannitol therapy revisited (1940-1997). Kidney Int 1997; 52:886-894, 1997.

14. Gadallah MF, Lynn M, Work J: Case report: Mannitol nephrotoxicity syndrome: Role of hemodialysis and postulate of mechanisms. Am J Med Sci 309: 219-222, 1995

15. Karajala V, Mansour W, Kellum JA. Diuretics in acute kidney injury. Minerva Anestesiol 2009; 75: 251-257.

16. Ho KM, Sheridan DJ. Meta-analysis of frusemide to prevent or treat acute renal failure. BMJ 2006; 333: 420. 
17. Llach F, Felsenfeld AJ, Haussler MR: The pathophysiology of altered calcium metabolism in rhabdomyolysis-induced acute renal failure. Interactions of parathyroid hormone, 25hydroxycholecalciferol, and 1,25-dihydroxycholecalciferol. N Engl J Med 1981;305: 117-123.

18. Vanholder R, Sever MS, Erek E, Lameire N: Rhabdomyolysis. J Am Soc Nephrol 2000; 11: 1553-1561.

19. Lane JT, Boudreau RJ, Kinlaw WB: Disappearance of muscular calcium deposits during resolution of prolonged rhabdomyolysis-induced hypercalcemia. Am J Med 1990;89: 523-525.

20. Knochel JP: Serum calcium derangements in rhabdomyolysis. N Engl J Med 1991;305: 161-163, 1981

21. Bosch X, Poch E, Grau JM. Rhabdomyolysis and Acute Kidney Injury. N Engl J Med. 2009 Jul 2;361(1):62-72.

22. Sheng ZY: Medical support in the Tangshan earthquake: A review of the management of mass casualties and certain major injuries. J Trauma 1987;27: 1130-1135.
23. Kazancioglu R, Cagatay A, Calangu S, Korular D, Turkmen A, Aysuna N, Sahin S, Bozfakioglu S, Sever MS: The characteristics of infections in crush syndrome. Clin Microbiol Infect 2002;8: 202-206.

24. Reis ND, Michaelson M. Crush injury to the lower limbs. Treatment of the local injury. J Bone Joint SurgAm 1986; 68:414-418.

25. Sever MS, Erek E, Vanholder R, et al. Renal replacement therapies in the aftermath of the catastrophic Marmara earthquake. Kidney Int 2002; 62:2264.

26. Ronco C: Extracorporeal therapies in acute rhabdomyolysis and myoglobin clearance. Crit Care 2005; 9:141-142

27. Sever MS, Erek E, Vanholder R, Koc M, Yavuz M, Aysuna N, Ergin H, Ataman R, Yenicesu M, Canbakan B, Demircan C, Lameire N: Lessons learned from the catastrophic Marmara earthquake: Factors influencing the final outcome of renal victims. Clin Nephrol 2004;61: 413-421. 